\title{
Faster Multistep Iterations for the Approximation of Fixed Points Applied to Zamfirescu Operators
}

\author{
Shin Min Kang, ${ }^{1}$ Ljubomir B. Ćirić, ${ }^{2}$ Arif Rafiq, ${ }^{3}$ Faisal Ali, ${ }^{4}$ and Young Chel Kwun ${ }^{5}$ \\ ${ }^{1}$ Department of Mathematics and RINS, Gyeongsang National University, Jinju 660-701, Republic of Korea \\ ${ }^{2}$ Faculty of Mechanical Engineering, University of Belgrade, Kraljice Marije 16, Belgrade 11000, Serbia \\ ${ }^{3}$ Department of Mathematics, Lahore Leads University, Lahore 54810, Pakistan \\ ${ }^{4}$ Centre for Advanced Studies in Pure and Applied Mathematics, Bahauddin Zakariya University, Multan 54000, Pakistan \\ ${ }^{5}$ Department of Mathematics, Dong-A University, Pusan 614-714, Republic of Korea
}

Correspondence should be addressed to Young Chel Kwun; yckwun@dau.ac.kr

Received 13 July 2013; Accepted 7 September 2013

Academic Editor: Salvador Romaguera

Copyright (c) 2013 Shin Min Kang et al. This is an open access article distributed under the Creative Commons Attribution License, which permits unrestricted use, distribution, and reproduction in any medium, provided the original work is properly cited.

By taking a counterexample, we prove that the multistep iteration process is faster than the Mann and Ishikawa iteration processes for Zamfirescu operators.

\section{Introduction}

Let $C$ be a nonempty convex subset of a normed space $E$, and let $T: C \rightarrow C$ be a mapping.

(a) For arbitrary $x_{0} \in C$, the sequence $\left\{x_{n}\right\}$ defined by

$$
x_{n+1}=\left(1-b_{n}\right) x_{n}+b_{n} T x_{n}, \quad n \geq 0,
$$

where $\left\{b_{n}\right\}$ is a sequence in $[0,1]$, is known as the Mann iteration process [1].

(b) For arbitrary $x_{0} \in C$, the sequence $\left\{x_{n}\right\}$ defined by

$$
\begin{gathered}
x_{n+1}=\left(1-b_{n}\right) x_{n}+b_{n} T y_{n}, \\
y_{n}=\left(1-b_{n}^{\prime}\right) x_{n}+b_{n}^{\prime} T x_{n}, \quad n \geq 0,
\end{gathered}
$$

where $\left\{b_{n}\right\}$ and $\left\{b_{n}^{\prime}\right\}$ are sequences in $[0,1]$, is known as the Ishikawa iteration process [2].

(c) For arbitrary $x_{0} \in C$, the sequence $\left\{x_{n}\right\}$ defined by

$$
\begin{gathered}
x_{n+1}=\left(1-b_{n}\right) x_{n}+b_{n} T y_{n}^{1}, \\
y_{n}^{i}=\left(1-b_{n}^{i}\right) x_{n}+b_{n}^{i} T y_{n}^{i+1}, \\
y_{n}^{p-1}=\left(1-b_{n}^{p-1}\right) x_{n}+b_{n}^{p-1} T^{n} x_{n}, \quad n \geq 0,
\end{gathered}
$$

where $\left\{b_{n}\right\}$ and $\left\{b_{n}^{i}\right\}, i=1,2, \ldots, p-2(p \geq 2)$, are sequences in $[0,1]$ and denoted by $\left(R S_{n}\right)$, is known as the multistep iteration process [3].

Definition 1 (see [4]). Suppose that $\left\{a_{n}\right\}$ and $\left\{b_{n}\right\}$ are two real convergent sequences with limits $a$ and $b$, respectively. Then, $\left\{a_{n}\right\}$ is said to converge faster than $\left\{b_{n}\right\}$ if

$$
\lim _{n \rightarrow \infty}\left|\frac{a_{n}-a}{b_{n}-b}\right|=0 .
$$

Definition 2 (see [4]). Let $\left\{u_{n}\right\}$ and $\left\{v_{n}\right\}$ be two fixed-point iteration procedures which, both, converge to the same fixed point $p$, say, with error estimates,

$$
\left\|u_{n}-p\right\| \leq a_{n}, \quad\left\|v_{n}-p\right\| \leq b_{n}, \quad n \geq 0,
$$

where $\lim a_{n}=0=\lim b_{n}$. If $\left\{a_{n}\right\}$ converges faster than $\left\{b_{n}\right\}$, then $\left\{u_{n}\right\}$ is said to converge faster than $\left\{v_{n}\right\}$.

Theorem 3 (see [5]). Let $(X, d)$ be a complete metric space, and let $T: X \rightarrow X$ be a mapping for which there exist real numbers $a, b$, and $c$ satisfying $a \in(0,1)$ and $b, c \in(0,1 / 2)$ such that, for each pair $x, y \in X$, at least one of the following is true:

$(z 1) d(T x, T y) \leq a d(x, y)$, 
$(z 2) d(T x, T y) \leq b[d(x, T x)+d(y, T y)]$,

$(z 3) d(T x, T y) \leq c[d(x, T y)+d(y, T x)]$.

Then, T has a unique fixed point $p$, and the Picard iteration $\left\{x_{n}\right\}$ defined by

$$
x_{n+1}=T x_{n}, \quad n \geq 0,
$$

converges to $p$ for any $x_{0} \in X$.

Remark 4. An operator $T$, which satisfies the contraction conditions $(z 1)-(z 3)$ of Theorem 3, will be called a Zamfirescu operator $[4,6,7]$.

In $[6,7]$, Berinde introduced a new class of operators on a normed space $E$ satisfying

$$
\|T x-T y\| \leq \delta\|x-y\|+L\|T x-x\|,
$$

for any $x, y \in E, 0 \leq \delta<1$, and $L \geq 0$.

He proved that this class is wider than the class of Zamfirescu operators.

The following results are proved in $[6,7]$.

Theorem 5 (see [7]). Let $C$ be a nonempty closed convex subset of a normed space $E$. Let $T: C \rightarrow C$ be an operator satisfying (4). Let $\left\{x_{n}\right\}$ be defined through the iterative process $\left(M_{n}\right)$ and $x_{0} \in C$. If $F(T) \neq \emptyset$ and $\sum_{n=0}^{\infty} b_{n}=\infty$, then $\left\{x_{n}\right\}$ converges strongly to the unique fixed point of $T$.

Theorem 6 (see [6]). Let $C$ be a nonempty closed convex subset of an arbitrary Banach space $E$, and let $T: C \rightarrow C$ be an operator satisfying (4). Let $\left\{x_{n}\right\}$ be defined through the iterative process $\left(I_{n}\right)$ and $x_{0} \in C$, where $\left\{b_{n}\right\}$ and $\left\{b_{n}^{\prime}\right\}$ are sequences of positive numbers in $[0,1]$ with $\left\{b_{n}\right\}$ satisfying $\sum_{n=0}^{\infty} b_{n}=\infty$. Then, $\left\{x_{n}\right\}$ converges strongly to the fixed point of T.

The following result can be found in [8].

Theorem 7. Let $C$ be a closed convex subset of an arbitrary Banach space E. Let the Mann and Ishikawa iteration processes with real sequences $\left\{b_{n}\right\}$ and $\left\{b_{n}^{\prime}\right\}$ satisfy $0 \leq b_{n}, b_{n}^{\prime} \leq 1$, and $\sum_{n=0}^{\infty} b_{n}=\infty$. Then, $\left(M_{n}\right)$ and $\left(I_{n}\right)$ converge strongly to the unique fixed point of $T$. Let $T: C \rightarrow C$ be a Zamfirescu operator, and, moreover, the Mann iteration process converges faster than the Ishikawa iteration process to the fixed point of $T$.

In [4], Berinde proved the following result.

Theorem 8. Let $C$ be a closed convex subset of an arbitrary Banach space $E$, and let $T: C \rightarrow C$ be a Zamfirescu operator. Let $\left\{y_{n}\right\}$ be defined by $\left(M_{n}\right)$ and $y_{0} \in C$ with a sequence $\left\{b_{n}\right\}$ in $[0,1]$ satisfying $\sum_{n=0}^{\infty} b_{n}=\infty$. Then, $\left\{y_{n}\right\}$ converges strongly to the fixed point of $T$, and, moreover, the Picard iteration $\left\{x_{n}\right\}$ converges faster than the Mann iteration.

Remark 9. In [9], Qing and Rhoades by taking a counterexample showed that the Mann iteration process converges more slowly than the Ishikawa iteration process for Zamfirescu operators.
In this paper, we establish a general theorem to approximate fixed points of quasi-contractive operators in a Banach space through the multistep iteration process. Our result generalizes and improves upon, among others, the corresponding results of Babu and Vara Prasad [8] and Berinde [4, 6, 7].

We also prove that the Mann iteration process and the Ishikawa iteration process converge more slowly than the multistep iteration process for Zamfirescu operators.

\section{Main Results}

We now prove our main results.

Theorem 10. Let $C$ be a nonempty closed convex subset of an arbitrary Banach space $E$, and let $T: C \rightarrow C$ be an operator satisfying (4). Let $\left\{x_{n}\right\}$ be defined through the iterative process $\left(R S_{n}\right)$ and $x_{0} \in C$, where $\left\{b_{n}\right\}$ and $\left\{b_{n}^{i}\right\}, i=1,2, \ldots, p-2(p \geq$ $2)$, are sequences in $[0,1]$ with $\sum_{n=0}^{\infty} b_{n}=\infty$. If $F(T) \neq \emptyset$, then $F(T)$ is a singleton, and the sequence $\left\{x_{n}\right\}$ converges strongly to the fixed point of $T$.

Proof. Assume that $F(T) \neq \emptyset$ and $w \in F(T)$. Then, using $\left(R S_{n}\right)$, we have

$$
\begin{aligned}
\left\|x_{n+1}-w\right\| & =\left\|\left(1-b_{n}\right) x_{n}+b_{n} T y_{n}^{1}-w\right\| \\
& =\left\|\left(1-b_{n}\right)\left(x_{n}-w\right)+b_{n}\left(T y_{n}^{1}-w\right)\right\| \\
& \leq\left(1-b_{n}\right)\left\|x_{n}-w\right\|+b_{n}\left\|T y_{n}^{1}-w\right\| .
\end{aligned}
$$

Now, for $x=w$ and $y=y_{n}^{1}$, (4) gives

$$
\left\|T y_{n}^{1}-w\right\| \leq \delta\left\|y_{n}^{1}-w\right\| .
$$

By substituting (6) in (5), we obtain

$$
\left\|x_{n+1}-w\right\| \leq\left(1-b_{n}\right)\left\|x_{n}-w\right\|+\delta b_{n}\left\|y_{n}^{1}-w\right\| .
$$

In a similar fashion, again by using $\left(R S_{n}\right)$, we can get

$$
\left\|y_{n}^{i}-w\right\| \leq\left(1-b_{n}^{i}\right)\left\|x_{n}-w\right\|+\delta b_{n}^{i}\left\|y_{n}^{i+1}-w\right\|,
$$

where $i=1,2, \ldots, p-2(p \geq 2)$ and

$$
\left\|y_{n}^{p-1}-w\right\| \leq\left(1-(1-\delta) b_{n}^{p-1}\right)\left\|x_{n}-w\right\| .
$$

It can be easily seen that, for $i=1,2, \ldots, p-2(p \geq 2)$, we have

$$
\begin{gathered}
\left\|y_{n}^{1}-w\right\| \leq\left(1-b_{n}^{1}\right)\left\|x_{n}-w\right\|+\delta b_{n}^{1}\left\|y_{n}^{2}-w\right\|, \\
\vdots \\
\left\|y_{n}^{p-3}-w\right\| \leq\left(1-b_{n}^{p-3}\right)\left\|x_{n}-w\right\|+\delta b_{n}^{p-3}\left\|y_{n}^{p-2}-w\right\|, \\
\left\|y_{n}^{p-2}-w\right\| \leq\left(1-b_{n}^{p-2}\right)\left\|x_{n}-w\right\|+\delta b_{n}^{p-2}\left\|y_{n}^{p-1}-w\right\| .
\end{gathered}
$$


Substituting (9) in (10) gives us

$$
\left\|y_{n}^{p-2}-w\right\| \leq\left(1-(1-\delta) b_{n}^{p-2}\left(1+\delta b_{n}^{p-1}\right)\right)\left\|x_{n}-w\right\| .
$$

It may be noted that, for $\delta \in[0,1)$ and $\left\{\eta_{n}\right\} \in[0,1]$, the following inequality is always true:

$$
1 \leq 1+\delta \eta_{n} \leq 1+\delta
$$

From (11) and (12), we get

$$
\left\|y_{n}^{p-2}-w\right\| \leq\left(1-(1-\delta) b_{n}^{p-2}\right)\left\|x_{n}-w\right\| .
$$

By repeating the same procedure, finally from (7) and (10), we yield

$$
\left\|x_{n+1}-w\right\| \leq\left[1-(1-\delta) b_{n}\right]\left\|x_{n}-w\right\| .
$$

By (14), we inductively obtain

$$
\left\|x_{n+1}-w\right\| \leq \prod_{k=0}^{n}\left[1-(1-\delta) b_{k}\right]\left\|x_{0}-w\right\|, \quad n \geq 0 .
$$

Using the fact that $0 \leq \delta<1,0 \leq b_{n} \leq 1$, and $\sum_{n=0}^{\infty} b_{n}=\infty$, it results that

$$
\lim _{n \rightarrow \infty} \prod_{k=0}^{n}\left[1-(1-\delta) b_{k}\right]=0
$$

which, by (15), implies that

$$
\lim _{n \rightarrow \infty}\left\|x_{n+1}-w\right\|=0 .
$$

Consequently, $x_{n} \rightarrow w \in F$, and this completes the proof.

Now, by a counterexample, we prove that the multistep iteration process is faster than the Mann and Ishikawa iteration processes for Zamfirescu operators.

Example 11. Suppose that $T:[0,1] \rightarrow[0,1]$ is defined by $T x=(1 / 2) x ; b_{n}=0=b_{n}^{p-1}=b_{n}^{i}, i=1,2, \ldots, p-1(p \geq$ 2 ), and $n=1,2, \ldots, 15 ; b_{n}=4 / \sqrt{n}=b_{n}^{p-1}=b_{n}^{i}, i=$ $1,2, \ldots, p-1(p \geq 2)$, and $n \geq 16$. It is clear that $T$ is a Zamfirescu operator with a unique fixed point 0 and that all of the conditions of Theorem 10 are satisfied. Also, $M_{n}=x_{0}=$ $I_{n}=R S_{n}, n=1,2, \ldots, 15$. Suppose that $x_{0} \neq 0$. For the Mann and Ishikawa iteration processes, we have

$$
\begin{aligned}
M_{n} & =\left(1-b_{n}\right) x_{n}+b_{n} T x_{n} \\
& =\left(1-\frac{4}{\sqrt{n}}\right) x_{n}+\frac{4}{\sqrt{n}} \frac{1}{2} x_{n} \\
& =\left(1-\frac{2}{\sqrt{n}}\right) x_{n} \\
& =\cdots=\prod_{i=16}^{n}\left(1-\frac{2}{\sqrt{i}}\right) x_{0},
\end{aligned}
$$

$$
\begin{aligned}
I_{n} & =\left(1-b_{n}\right) x_{n}+b_{n} T\left(\left(1-b_{n}^{\prime}\right) x_{n}+b_{n}^{\prime} T x_{n}\right) \\
& =\left(1-\frac{4}{\sqrt{n}}\right) x_{n}+\frac{4}{\sqrt{n}} \frac{1}{2}\left(1-\frac{2}{\sqrt{n}}\right) x_{n} \\
& =\left(1-\frac{2}{\sqrt{n}}-\frac{4}{n}\right) x_{n} \\
& =\cdots=\prod_{i=16}^{n}\left(1-\frac{2}{\sqrt{i}}-\frac{4}{i}\right) x_{0}, \\
& R S_{n}=\left(1-b_{n}\right) x_{n}+b_{n} T y_{n}^{1}, \\
\quad y_{n}^{i}=\left(1-b_{n}^{i}\right) x_{n}+b_{n}^{i} T y_{n}^{i+1}, & \\
y_{n}^{p-1}= & \left(1-b_{n}^{p-1}\right) x_{n}+b_{n}^{p-1} T x_{n}, \quad n \geq 0,
\end{aligned}
$$

where $i=1,2, \ldots, p-2(p \geq 2)$ implies that

$$
\begin{aligned}
R S_{n} & =\left(1-\sum_{j=1}^{p}\left(\frac{2}{\sqrt{n}}\right)^{j}\right) x_{n} \\
& =\cdots=\prod_{i=16}^{n}\left(1-\sum_{j=1}^{p}\left(\frac{2}{\sqrt{i}}\right)^{j}\right) x_{0} .
\end{aligned}
$$

Now, consider

$$
\begin{aligned}
\left|\frac{R S_{n}-0}{M_{n}-0}\right| & =\left|\frac{\prod_{i=16}^{n}\left(1-\sum_{j=1}^{p}(2 / \sqrt{i})^{j}\right) x_{0}}{\prod_{i=16}^{n}(1-(2 / \sqrt{i})) x_{0}}\right| \\
& =\left|\frac{\prod_{i=16}^{n}\left(1-\sum_{j=1}^{p}(2 / \sqrt{i})^{j}\right)}{\prod_{i=16}^{n}(1-(2 / \sqrt{i}))}\right| \\
& =\left|\prod_{i=16}^{n}\left(1-\frac{\sum_{k=2}^{p}(2 / \sqrt{i})^{k}}{1-(2 / \sqrt{i})}\right)\right| \\
& =\left|\prod_{i=16}^{n}\left(1-\frac{\sum_{k=2}^{p}(2 / \sqrt{i})^{k} \sqrt{i}}{\sqrt{i}-2}\right)\right| .
\end{aligned}
$$

It is easy to see that

$$
\begin{aligned}
0 & \leq \lim _{n \rightarrow \infty} \prod_{i=16}^{n}\left(1-\frac{\sum_{k=2}^{p}(2 / \sqrt{i})^{k} \sqrt{i}}{\sqrt{i}-2}\right) \\
& \leq \lim _{n \rightarrow \infty} \prod_{i=16}^{n}\left(1-\frac{1}{i}\right) \\
& =\lim _{n \rightarrow \infty} \frac{15}{n} \\
& =0 .
\end{aligned}
$$

Hence,

$$
\lim _{n \rightarrow \infty}\left|\frac{R S_{n}-0}{M_{n}-0}\right|=0 .
$$


Thus, the Mann iteration process converges more slowly than the multistep iteration process to the fixed point 0 of $T$.

Similarly,

$$
\begin{aligned}
\left|\frac{R S_{n}-0}{I_{n}-0}\right| & =\left|\frac{\prod_{i=16}^{n}\left(1-\sum_{j=1}^{p}(2 / \sqrt{i})^{j}\right) x_{0}}{\prod_{i=16}^{n}(1-(2 / \sqrt{i})-(4 / i)) x_{0}}\right| \\
& =\left|\frac{\prod_{i=16}^{n}\left(1-\sum_{j=1}^{p}(2 / \sqrt{i})^{j}\right)}{\prod_{i=16}^{n}(1-(2 / \sqrt{i})-(4 / i))}\right| \\
& =\left|\prod_{i=16}^{n}\left(1-\frac{\sum_{k=3}^{p}(2 / \sqrt{i})^{k}}{1-(2 / \sqrt{i})-(4 / i)}\right)\right| \\
& =\left|\prod_{i=16}^{n}\left(1-\frac{\sum_{k=3}^{p}(2 / \sqrt{i})^{k} i \sqrt{i}}{i \sqrt{i}-2 i-4 \sqrt{i}}\right)\right|,
\end{aligned}
$$

with

$$
\begin{aligned}
0 & \leq \lim _{n \rightarrow \infty} \prod_{i=16}^{n}\left(1-\frac{\sum_{k=3}^{p}(2 / \sqrt{i})^{k} i \sqrt{i}}{i \sqrt{i}-2 i-4 \sqrt{i}}\right) \\
& \leq \lim _{n \rightarrow \infty} \prod_{i=16}^{n}\left(1-\frac{1}{i}\right) \\
& =\lim _{n \rightarrow \infty} \frac{15}{n} \\
& =0,
\end{aligned}
$$

implies that

$$
\lim _{n \rightarrow \infty}\left|\frac{R S_{n}-0}{I_{n}-0}\right|=0 .
$$

Thus, the Ishikawa iteration process converges more slowly than the multistep iteration process to the fixed point 0 of $T$.

\section{Conflict of Interests}

The authors declare that there is no conflict of interests regarding the publication of this paper.

\section{Acknowledgments}

The authors would like to thank the editor and the referees for their useful comments and suggestions. This study was supported by research funds from Dong-A University.

\section{References}

[1] W. R. Mann, "Mean value methods in iteration," Proceedings of the American Mathematical Society, vol. 4, pp. 506-510, 1953.

[2] S. Ishikawa, "Fixed points by a new iteration method," Proceedings of the American Mathematical Society, vol. 44, pp. 147-150, 1974.
[3] B. E. Rhoades and S. M. Soltuz, "The equivalence between Mann-Ishikawa iterations and multistep iteration," Nonlinear Analysis. Theory, Methods \& Applications, vol. 58, no. 1-2, pp. 219-228, 2004

[4] V. Berinde, "Picard iteration converges faster than Mann iteration for a class of quasi-contractive operators," Fixed Point Theory and Applications, no. 2, pp. 97-105, 2004.

[5] T. Zamfirescu, "Fix point theorems in metric spaces," Archiv der Mathematik, vol. 23, pp. 292-298, 1972.

[6] V. Berinde, "On the convergence of the Ishikawa iteration in the class of quasi contractive operators," Acta Mathematica Universitatis Comenianae, vol. 73, no. 1, pp. 119-126, 2004.

[7] V. Berinde, "A convergence theorem for some mean value fixed point iteration procedures," Demonstratio Mathematica, vol. 38, no. 1, pp. 177-184, 2005.

[8] G. V. R. Babu and K. N. V. V. Vara Prasad, "Mann iteration converges faster than Ishikawa iteration for the class of Zamfirescu operators," Fixed Point Theory and Applications, vol. 2006, Article ID 49615, 6 pages, 2006.

[9] Y. Qing and B. E. Rhoades, "Comments on the rate of convergence between Mann and Ishikawa iterations applied to Zamfirescu operators," Fixed Point Theory and Applications, vol. 2008, Article ID 387504, 3 pages, 2008. 


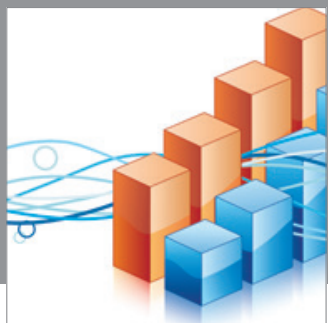

Advances in

Operations Research

mansans

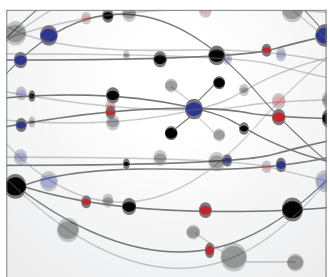

The Scientific World Journal
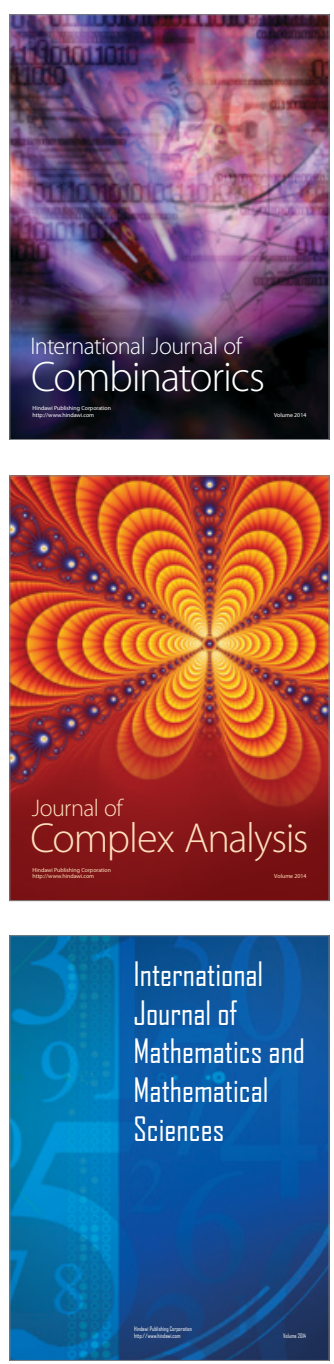
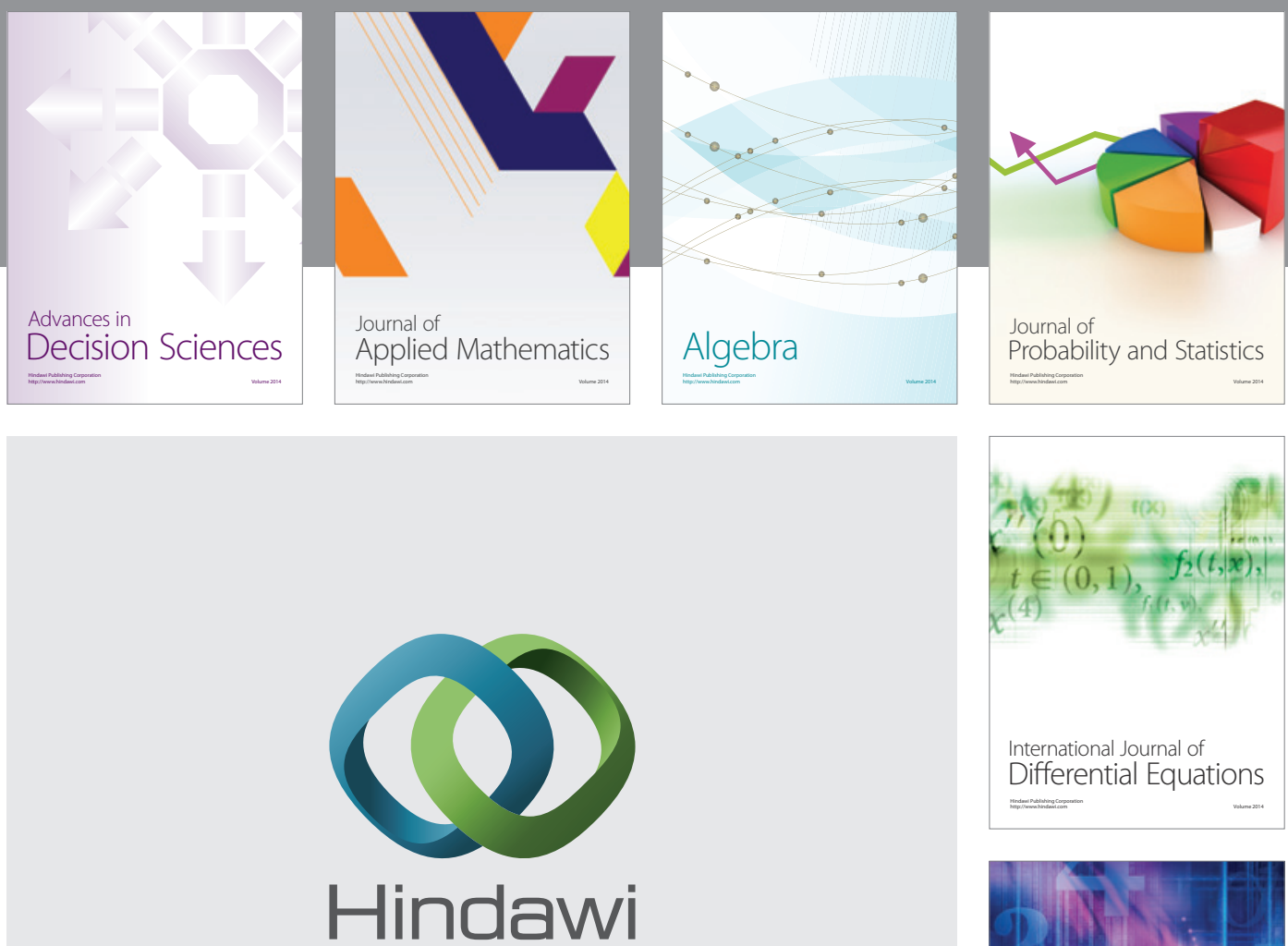

Submit your manuscripts at http://www.hindawi.com
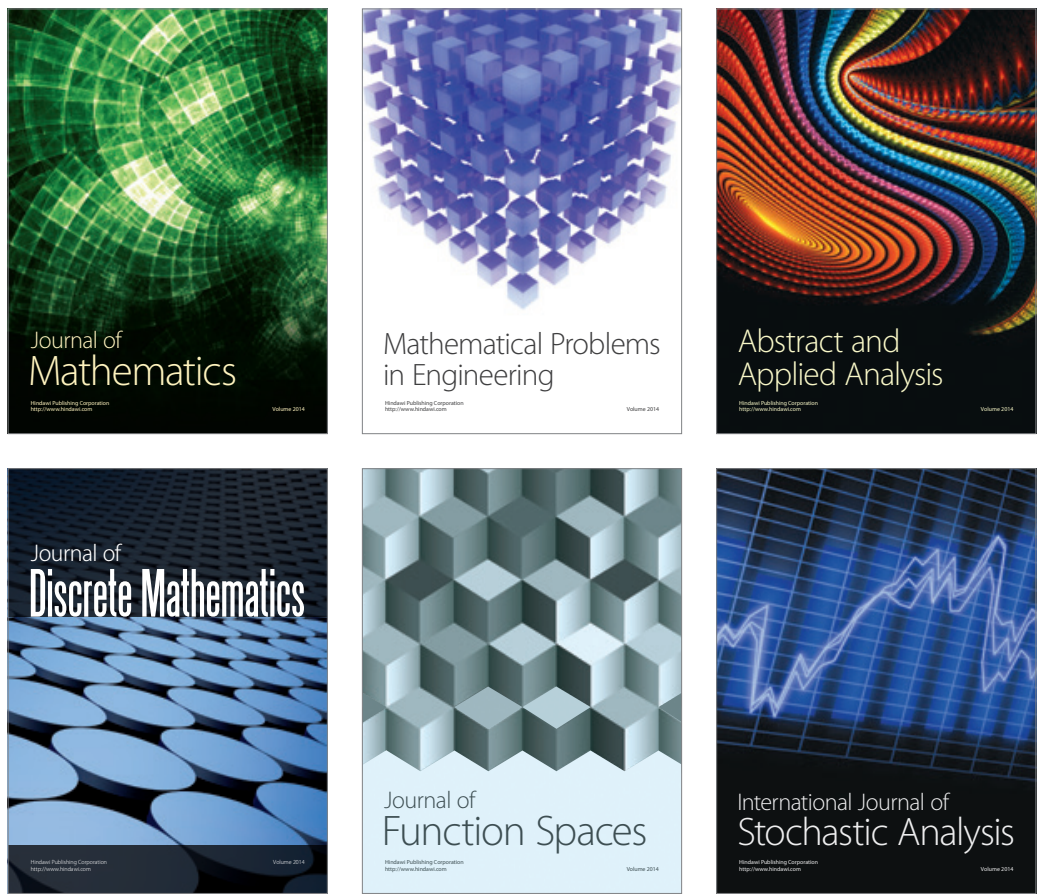

Journal of

Function Spaces

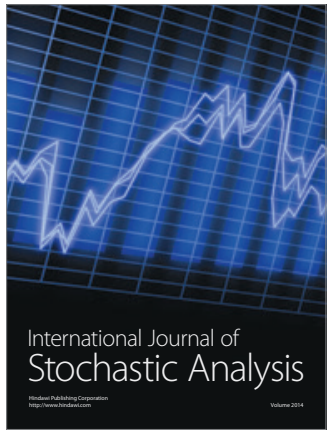

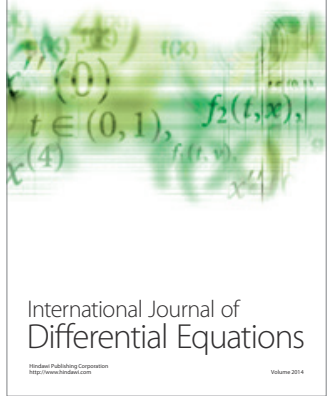
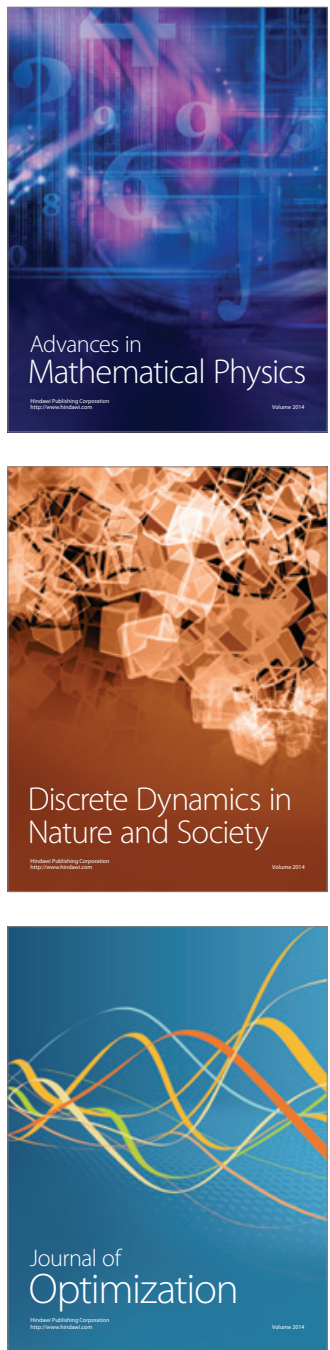